the scheme's main source of money for basic research - the Research Projects of National Relevance programme - last made a grant call in 2017 . Moreover, Italy invests only $1.2 \%$ of its gross domestic product in research - far below the European Union target of 3\%.

Many scientists had hoped for an agency that would simplify research funding, but note that the ANR instead adds another organization with its own budget. And it is not yet clear how the ANR would interact with Italy's other science-funding mechanisms. The bill up for discussion states that the agency would coordinate the direction of research at universities and public research bodies, fund "highly strategic" projects and encourage Italian participation in European and international research initiatives. It would receive $€ 25$ million in 2020 , $€ 200$ million in 2021 and $€ 300$ million per year from 2022.

\title{
Missed opportunity
}

"It is promising that the matter is part of the current government's strategy. Unfortunately, the model behind it is not yet clear," says Vincenzo Costanzo, a cancer researcher at IFOM, a molecular-oncology institute in Milan. The move is a missed opportunity to bring all government research funding under a single body in a transparent and independent manner, he adds. "We really need an agency that regulates the annual grant calls."

Researchers also worry that they have not been involved in the ANR's planning, and are concerned about the agency's political independence. According to the bill, the ANR's leaders will be appointed mainly by politicians: the prime minister would choose the director, and government ministers would select most of the agency's eight-member executive committee. Many had instead hoped for an agency overseen by research managers and scientific advisers.

Overall, the agency is a positive step, says Giuseppe Remuzzi, director of the Mario Negri Institute for Pharmacological Research in Bergamo. But the government's role should be restricted to making suggestions about appointments, and executive-committee members should be chosen by a group operating under the best practices used by the international scientific community, he says.

Lorenzo Fioramonti, Italy's research minister, says that scientists should feed into the ANR's development. He was involved in the idea to create the agency, but says he was surprised that the draft law also included information on the agency's governance. "The agency's function and governance can only be decided after a discussion with the research community," he says. Fioramonti had hoped that the bill would serve only to set up the agency, with details of its governance and grant management decided early next year.

\section{FIRST VACCINEAGAINST DEADLYEBOLA VIRUS WINSAPPROVAL}

\begin{abstract}
The shot has already been given to hundreds of thousands of people in ongoing Africa outbreak.
\end{abstract}

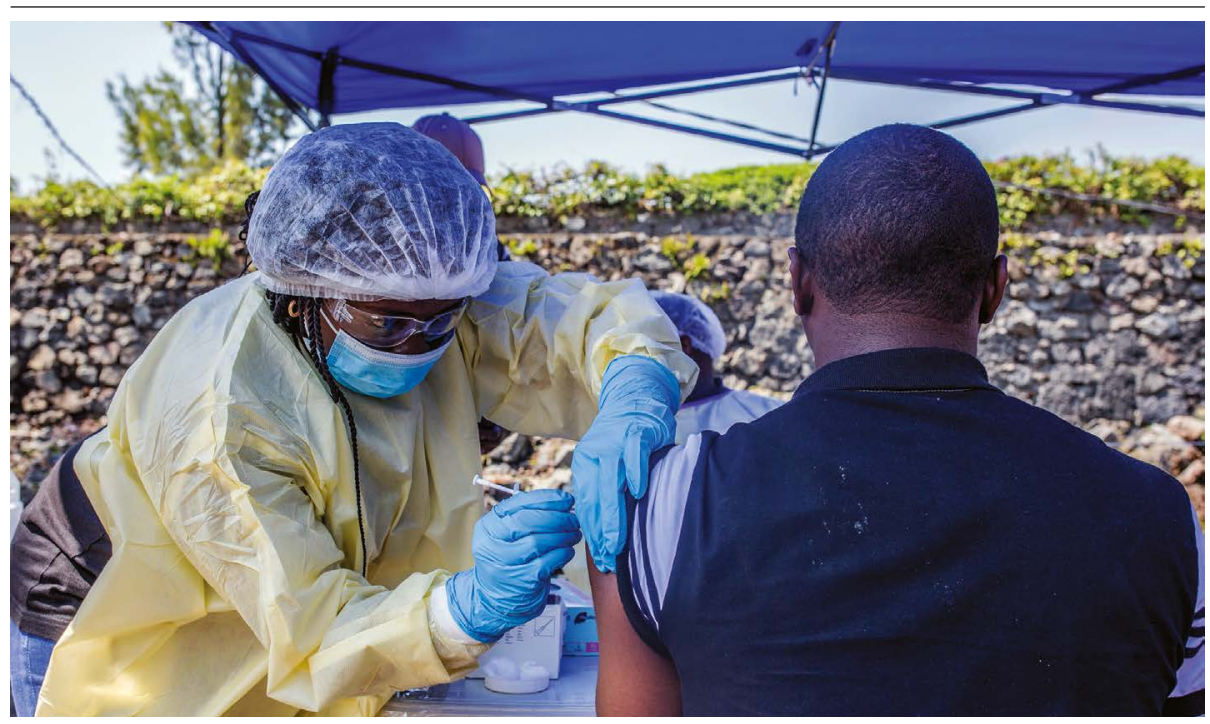

An Ebola vaccine has been approved by the European Medicines Agency.

\section{By Ewen Callaway}

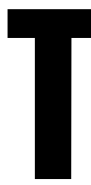

he world finally has an Ebola vaccine. On 11 November, European regulators approved a vaccine that has already helped to control deadly outbreaks of the virus - the first time any immunization against Ebola has passed this hurdle.

The decision by the European Medicines Agency (EMA) to allow US pharmaceutical company Merck to market its vaccine means that the product can now be stockpiled and, potentially, distributed more widely than it is now, particularly in Africa. In 2015, Gavi, the Vaccine Alliance - a global health partnership based in Geneva, Switzerland, that funds vaccine distribution in low-income countries - told manufacturers that it would commit to purchasing their Ebola vaccines once they had been approved by a "stringent health authority", such as the EMA.

Although several other vaccines against Ebola - a haemorrhagic fever that causes severe diarrhoea, vomiting and bleeding are in development, Merck's is the only one that has been tested during an outbreak, in which it was shown to be highly effective at preventing infection.

The vaccine, first patented in 2003 , has been administered on an emergency basis to quell the ongoing outbreak in the Democratic Republic of the Congo (DRC), which has killed some 2,000 people since it started last year. It was also used during a 2018 outbreak in that country, and in Guinea in 2015. In the current outbreak, hundreds of thousands of people have received the Merck shot, including more than 60,000 health-care workers in the DRC and several neighbouring countries.

"This is a vaccine with huge potential," said Seth Berkley, chief executive of Gavi, in a press release after the EMA's decision. "It has already been used to protect more than 250,000 people in the DRC and could well make major Ebola outbreaks a thing of the past." The organization has supported the stockpiling and delivery of Ebola vaccines and hopes to build up a global supply that could be rolled out quickly during future outbreaks.

\section{Future protection}

The EMA's approval "makes a big difference", says David Heymann, an epidemiologist at the London School of Hygiene and Tropical Medicine. But he stresses that research into the Merck vaccine and development of others must continue. "The message is that the research is not done," he adds. Research could help to develop vaccines that offer longer-lasting immunity, target more than one species of Ebola and are easier to store.

Merck's vaccine, which is marketed under the name Ervebo and known to researchers as rVSV-ZEBOV-GP, was tested in a clinical trial 
conducted in Guinea towards the end of the 2014-16 Ebola outbreak in West Africa. There, the vaccine was administered to people who had been in contact with someone who was infected with Ebola, and to their subsequent contacts. It was found to offer a high level of protection against infection.

Health workers have used this strategy known as ring vaccination - in the two other outbreaks in which rVSV-ZEBOV-GP had been deployed. But Heymann says it's important to determine whether the Merck vaccine has other uses - for instance, preventive administration to emergency health workers who might encounter Ebola in the distant future. For this, researchers will need to determine how long the vaccine's protection lasts, and whether a 'booster' dose can extend immunity.

Such studies are in the works with rVSV-ZEBOV-GP and competing vaccines, says Adrian Hill, a vaccinologist at the University of Oxford, UK. "The question remains, which vaccine would you give to, say, health-care workers to prevent them getting Ebola?"

Merck's product protects against the Zaire species of the Ebola virus, which is behind the current DRC outbreak and the 2014-16 West Africa outbreak. It will be important to develop vaccines against other species of the virus - especially the Sudan species, which has caused seven known outbreaks since 1976, says Hill, who helped to test an Ebola vaccine that the London-based pharmaceutical company GlaxoSmithKline shelved in August.

There are seven other Ebola vaccines in various stages of clinical testing, according to the World Health Organization (WHO) in Geneva. In September 2019, the WHO announced that a vaccine manufactured by Johnson \& Johnson in New Brunswick, New Jersey, would be used in the current DRC outbreak. Last week, the company submitted that vaccine for EMA approval.

Unlike the Merck vaccine, which is given in one dose, the Johnson \& Johnson immunization requires a booster shot that is administered 56 days after the first injection. In the DRC, it will be given to people at risk of Ebola, such as health-care workers, in areas where the virus is not already circulating.

And next month, Gavi's board will decide whether to establish a global stockpile of Ebola vaccines. Merck, which is headquartered in Kenilworth, New Jersey, is seeking approval for its vaccine by the US Food and Drug Administration.

On 12 November, the WHO announced it had "prequalified" the Merck vaccine, which means that the product meets the agency's standards for quality, safety and efficacy. Other UN agencies, Gavi and many national health agencies look to this endorsement when procuring and delivering a vaccine.

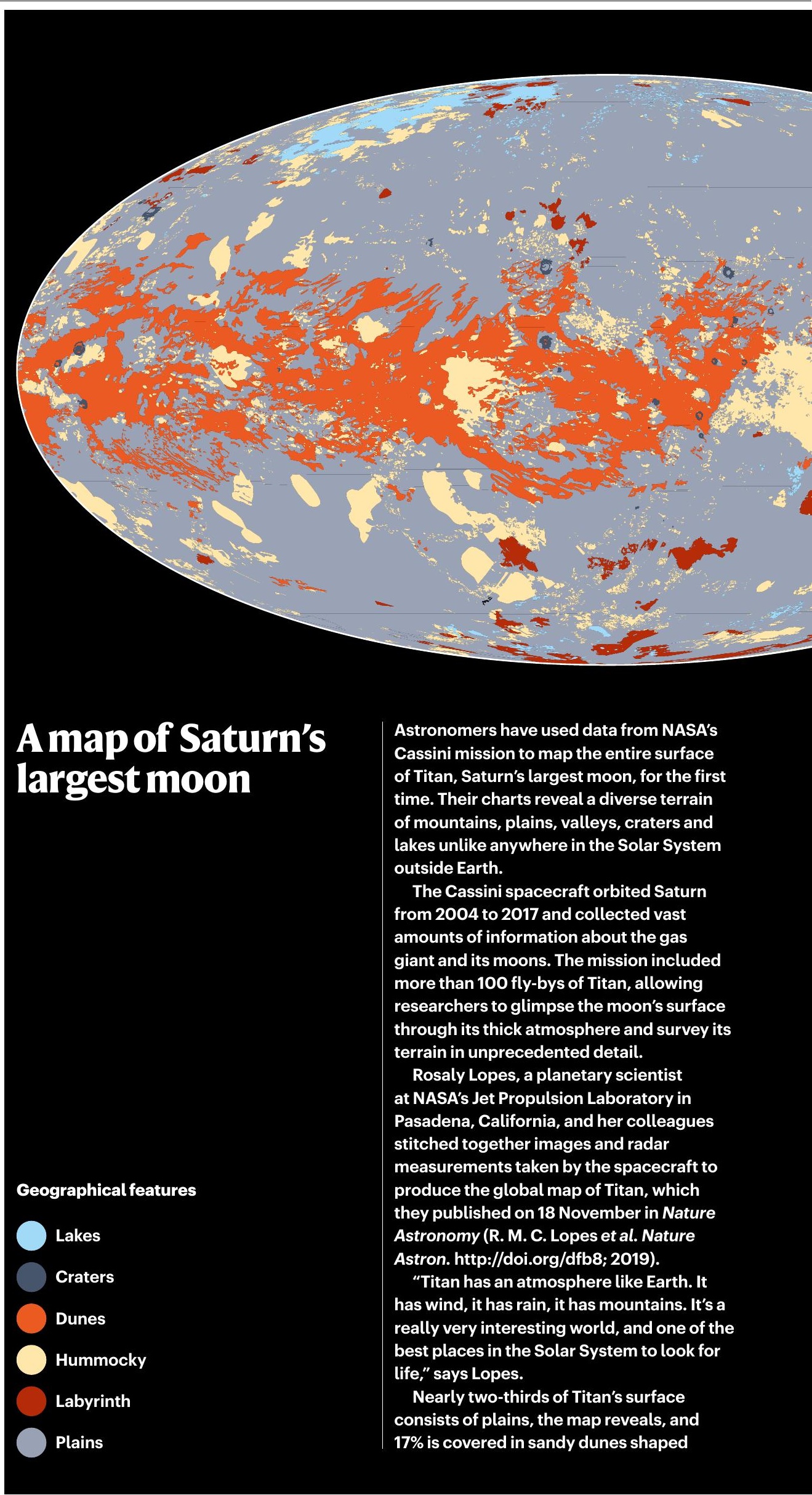

